\title{
EVALUATION OF METHOTREXATE IN THE MANAGEMENT OF UNDISTURBED TUBAL ECTOPIC PREGNANCY
}

\author{
Mostafa M. Zaitoun; Hossam A. Ibrahim; Hala S. El Sayed and Samah M. Ali \\ Obstetrics and Gynecology Department, Faculty of Medicine, Zagazig University
}

\section{ABSTRACT}

Background: Ectopic pregnancy is a pregnancy with the zygot implanted out side the endometrium of the uterine cavity. $95 \%$ of ectopics are in the tube, $1.5 \%$ abdominal, $0.5 \%$ ovarian and $0.03 \%$ are in the cervix. EP can be diagnosed by serial quantitive beta subunite of human chorionic gonadotrophin hormone and transvaginal ultrasound. Methotrexate injtion give high success rates (86 to 94\%) that are not skill-dependent and has become a standard medical treatment in appropriate patients. The best suitable cases for MTX therapy for undisturbed ectopic pregnancy are those who are not suffering symptoms, have a blood level of Q B-hCG of less than $5000 \mathrm{mIU} / \mathrm{ml}$, tubal size less than $3.5 \mathrm{~cm}$, no fetal cardiac activity on US, and will come in to be followed closely. MTX is typically given by injection and this method increases absorption of all of the medicine. Common side effects of MTX treatment for undisturbed EP include: abdominal pain, vaginal bleeding, nausea and vomiting and dizziness. Women diagnosed with an EP were considered candidates for treatment with MTX injection if they were hemodynamically stable, did not have free fluid outside the pelvic cavity on US examination, did not desire surgery and agreed to weekly follow-up visits until the level of serum Q B- hCG was fifty mIU per ml or lower. Aim of the work: To evaluate the fate of undisturbed tubal EP after injection of MTX. Patients and methods: This prospective study was carried out at the Department of Obstetrics and Gynecology, Zagazig University Hospitals on 54 women with undisturbed EP. The women were informed regarding the treatment and were consented. We gave single dose of MTX $\left(50 \mathrm{mg} / \mathrm{m}^{2}\right.$ of body surface area) to the patients. Q B-hCG were followed on day one (injection day), day four and on day seven. We administered 2nd dose of MTX if the level of quantitive of beta subunite on seven ${ }^{\text {th }}$ day had not decreased by at least twenty five percent from the first day level and the protocol was repeated. If decrease in quantitive beta subunite between days four and seven was less than fifty percent, asecond dose of MTX $\left(50 \mathrm{mg} / \mathrm{m}^{2}\right)$ was given. Weekly measurements were continued until the quantitive beta subunite is undetectable. If quantitive beta subunite falls < fifty percent between weekly measurements after third dose, we perform laparoscopic salpingostomy or salpingectomy. Results: In current study the level of Q B-hCG in the studied cases pre-injection ranged from 397 to $7102 \mathrm{mIU} / \mathrm{ml}$, its mean was $4231.9 \pm 2210.3 .4$ th day level ranged from 107 to 7400 and its mean was $3881.7 \pm 2317.6 \mathrm{mIU} / \mathrm{ml}$. 7th day level ranged from 30 to $7900 \mathrm{mIU} / \mathrm{ml}$ and its mean was $2566.9 \pm 2145.6 \mathrm{mIU} / \mathrm{ml}$. The success rate in the current study was $83.3 \%$ classified as follow:44 patients (81.48\%) recived single dose of MTX. 10 patients $(18.52 \%)$ recived multiple doses one week a part ( need prolonged follow up that exceeded 30 days). 6 patients $(11.1 \%)$ had laparoscopic management and 3 patients $(5.6 \%)$ had urgent laparotomy. Conclusion: There is no pathognomonic pain or findings on examination that are diagnostic for tubal pregnancy.Also the diagnosis of tubal pregnancy ,as early as 6-7 weeks postmenstrual by screening of all suspected pregnancies may be the key for optimal use of medical treatment. Transvaginal ultrasound and serial quantitive beta subunite are highly successful in early detection of EP.Medical management by methotrexate injection is safe and cost effective for the reolution of ectopic pregnancy proplem.

Key Words: methotrexate,ectopic pregnancy,tranvaginal ultrasound.

\section{Corresponding author: Samah Mostafa Ali}

Mobile: +201272052055

\section{INTRODUCTION}

T There is marked elevation in the incidence of ectopic pregnancy in recent years, to approximately $2 \%$ of all pregnancies. The best line of treatment either (invasive, medical or expectant management) this dependent on accurate and early diagnosis of EP this increase the chance of retaining tubal function $^{[1]}$.

The main principle has become a conservative approach that help to save the
Received: November 2015

Accepted: January 2016 tubal function, rather than salpingectomy. Hemorrhage from EP is still the main cause of pregnancy related maternal death in the first trimester and accounts form four to ten percent of all pregnancy related deaths, but improved diagnostic methods leading to earlier detection and treatment ${ }^{[2]}$.

Methotrxate is an excellent alternative therapy to surgery for special types of EP that carry the greatest risk of haemorrhage such as 
cervical, abdominal and cornual ectopic pregnancies ${ }^{[3]}$.

Methotrexate, which was first described by Stovall TG is the most commonly used one because of its simplicity and convenience for both clinician and patient $^{[4]}$, and decrease the need for surgery and the associated side effects.

Although, there is association with risk of side effects due to injection of MTX, as stomatitis and conjunctivitis, they are usually mild and self-limiting. Thirty percent of patients who receive single-dose management and fourty percent of those who receive multi-dose management show side effects[5]. Also, there is association of failure rate about ten percent to twenty percent for the single-dose therapy and six percent to thirty percent for the multidose therapy and this group of patients requires surgical intervention $^{[6]}$.

The success of MTX therapy is dependent on the adherence to inclusion criteria. The success rate for single-dose therapy has been reported to be eighty percent to ninety percent and seventy percent to ninety four percent for multi-dose therapy[7].

the aim of the study is to evaluate the role of $\mathrm{mtx}$ in management of undisturbed tubal ectopic pregnancy.

\section{PATIENTS AND METHODS}

This interventional cohort study was carried out in the Emergency Unit at the Department of Obstetrics and Gynecology, Zagazig University Hospitals between August 2012 to December 2014 on 54 women diagnosed as undisturbed EP.

All cases were subjected to: full history taking, examination, including general examination, abdominal examination (inspection, palpation, and percussion) and vaginal examination (bimanual examination) if necessary and with caution.

Ultrasound was routinely done for all admitted cases. Most of the US criteria for the diagnosis of EP were fulfilled in the cases of the study. These criteria included:

1. Documentation of the absence of intrauterine pregnancy criteria inspite of high Q B-hCG (higher than $1500 \mathrm{IU} / \mathrm{ml}$ ).

2. The presence of amorphous material (mostly blood clot) or gestational structures (the yolk sac or fetal pole) within the dilated fallopian tube.

3. The presence of suspected findings such as tubal ring or its reminants (higher echogenic mass) related to the ovary (relatively of lower echogenicity) and the mass slide separately from the ovary if gently pushed by the vaginal proble.

4. The presence or absence of free fluid in the cul- de-sac which is important in cases of leaking or ruptured tubal pregnancy.

\section{Inclusion criteria:}

- Confirmed diagnosis of ectopic pregnancy and feasibility to medical management.

- Transvaginal ultrasound visualization of a gestational sac in the adnexa, with or without fetal pole.

- Absence of cardiac pulsation of the fetus.

- Mass size of EP less than $3.5 \mathrm{~cm}$.

- The woman is hemodynamically stable without signs of hemoperitoneum.

- The woman is able to return for frequent follow-up care or to stay as in patient.

- Normal renal and liver function had been documented within 2 days.

- Normal white blood count and platelet count had been documented as per laboratory standard.

- Normal chest X-ray was obtained if the patient has a history of pulmonary disease.

- No history of allergy or sensitivity to methotrexate or any component of its formulation.

\section{Exclusion criteria:}

- Internal haemorrhage and deterioration of general conditions of the patient.

- Signs of impending or ongoing rupture of EP mass, as severe or persistenet abdominal pain or presence of more than $300 \mathrm{ml}$ of free peritoneal fluid outside the pelvic cavity.

- Hypersensitivity to MTX.

- Coexistent viable intrauteirne pregnancy.

- Bresatfeeding.

- Laboratory evidence of immunodeficiency.

- Alcoholism or chronic liver disease.

- The concomitant use of non-steroidal antiinflammatory drugs. 
- Blood dyscrasia such as leukopenia, thrombocytopenia, or severe anemia.

- Active pulmonary disease.

- Hepatic, renal, or hematological dysfunction.

- Adnexal mass $\geq 3.5 \mathrm{~cm}$.

- Presence of cardiac pulsation of the fetus.

- Presence of psychiatric disease such as depression, bipolar disease, psychotic disorder, or drug addiction.

- Women not reliable to comply with study measures and follow up.

\section{Pretreatment testing:}

- Q B-hCG, blood type, CBC, renal and liver functions.

- Transvaginal ultrasound.

\section{Precautions done during therapy:}

- Avoid vaginal intercourse.

- $\quad$ Avoid PV examinations during follow up of MTX therapy due to risk of rupture of the tube.

- Avoid direct exposureto sun rays to limit risk of skin inflammation caused by MTX.

- Avoid drugs and foods that containing folic acid.

- Avoid administration of NSAIDs as the interaction with MTX may cause suppression of bone marrow, aplastic anemia or GIT toxicity.

\section{Single-dose protocol given to patient:}

Before administration of MTX, the patients must be counseled on the risks, benefits, adverse effects, and possibility of failure of MTX treatment, which would lead to rupture of the tube and that need surgical intervention. The patients should be aware of the signs and symptoms associated with rupture of the tube and be advised to ask their doctors with worsening of abdominal pain or tenderness, dizziness, tachycardia, palpitations, or syncope.

\section{Follow up:}

Q B-hCG was followed on day one (injection day), day four, on day seven.

We administered a 2nd dose of MTX if concentration ofquantitive beta subunite on $7^{\text {th }}$ day had not decreased by at least twenty five percent from level of $1^{\text {st }}$ day and this is repeated.
If decrease in quantitive beta subunite between fourth and seventh day is less than fifteen percent, a second dose of MTX 50 $\mathrm{mg} / \mathrm{m}^{2}$ was given.

Continous measurement of quantitive beta subunite is repeated every week until it is become undetectable.

Usually decline to less than 15 $\mathrm{mIU} / \mathrm{ml}$ we gave maximum 3 doses of MTX.

If falling of quantitive beta subuniteQ $\mathrm{B}-\mathrm{hCG}$ is less than fifteen percent between measurement every weeks after third dose, laparoscopic intervention should be done.

Follow-up was by transvaginal ultrasound, serial Q B-hCG levels and monitoring for side effects of methotrexate.

Women with severe abdominal pain

US evaluation for detection of peritoneal fluid is indicated for them.

After MTX therapy, we reported the fate of follow-up as follow:

- Patients respond well to therapy with minimal side effects as stomatitis(dyspepsia and heart burn) and conjunctivitis.

- Patients respond to therapy but with more troublesome side effects as inflammation of GIT, skin, lung,loss of hair, elevation of liver enzymes, and suppression of bone marrow.

- Patients needed laparoscopic management.

- Patients needed urgent laparotomy.

\section{STATISTICAL ANALYSIS}

- The results was considered: Significant when the probability of error is less than five percent $(\mathrm{p}<0.05)$.

- Non-significant when the probability of error is more than five percent ( $\mathrm{p}>0.05)$.

- Highly significant when the probability of error is less than zero point one percent ( $\mathrm{p}<$ 0.001 ).

The smaller the p-value obtained, the more significant are the results.

\section{RESULTS}

Table (1) shows that the age group ranged from 20 to 38 years old. Its mean was $27.9 \pm 4.5$. The gestational age at diagnosis in the studied cases ranged from 5 to 8 weeks, its mean was $6.4 \pm 1.1$.

Table (2) shows that 31 patients $(69.8 \%)$ had normal vaginal delivery and 13 patients $(30.2 \%)$ had cesarean section. 37 
patients (67.9) had parity $\leq 3$ and 17 patients $(32.1 \%)$ had parity $>4.38(69.8 \%)$ patients had no history of abortion while the other 16 patients $(30.2 \%)$ had positive history of abortion. There are no statistically significant effect of the mode of delivery, parity and abortion on current ectopic pregnancy $\mathrm{P}>0.05$.

Table (3) shows that 50 patients $(92.6 \%)$ had no history of previous ectopic pregnancy, while the other 4 patients $(7.4 \%)$ had positive history. 43 patients $(79.6 \%)$ had no history of pelvic inflammatory disease, while the other 11 patients $(20.4 \%)$ had positive history. 35 patients $(64.2 \%)$ did not used intrauterine contraceptive device, while the other 19 patients $(35.8 \%)$ used it. There are no statistically significant effect of previous ectopic, pelvic inflammatory disease or intrauterine contraceptive device on current ectopic pegnancy $\mathrm{P}>0.05$.

Table (4) shows that there were 35 patients $(64.8 \%)$ complained of vaginal bleeding ,52 patients (96.3\%) complained of pain either lower abdominal pain and tenderness mainly on the affected side,or with cervical movement during vaginal examination or by vaginal probe during transvaginal examination, 50 patients $(92.6 \%)$ complained of amenorrhea. There are no statistically significant effect $\mathrm{P}>0.05$.

Table (5) shows that the cases who required single methotrexate dose were (44 patients) and who required multiple doses of methotrexate $(\geq 2)$ were (10 patients) as regard pre treatment, $4^{\text {th }}$ day and $7^{\text {th }}$ day level of Q BhCG. The pre injection level of Q B- hCG in the studied cases ranged from 397 to 7102 $\mathrm{mIU} / \mathrm{ml}$, its mean was $4231.9 \pm 2210.3$. The $4^{\text {th }}$ day level of Q B- hCG in the studied cases ranged from 107 to 7400 and its mean was $3881.7 \pm 2317.6 \mathrm{mIU} / \mathrm{ml}$. The seventh day level of Q B-hCG ranged from 30 to 7900 $\mathrm{mIU} / \mathrm{ml}$ and its mean $2566.9 \pm 2145.6$ $\mathrm{mIU} / \mathrm{ml}$.

There was non statistically significant difference between patients who required single dose and those who required multiple doses of methotrexate as regard the pre injection Q B-hCG level . P value $>0.05$ There was a high statistically significant difference in the $4^{\text {th }}$ day Q B-hCG in patients who required single dose and those who required multiple doses of methotrexate $\mathrm{P}<0.05$.

Table (6) shows that there were 32 case with adnexal mass size from $0-2 \mathrm{~cm}$ and success rate of treatment was $100 \%$, while there were 22 case with adnexal mass size more than $2 \mathrm{~cm}$ out of them 13 case were cured with success rate $59.09 \%$.

Figures (1), (2) and (3) show that There was a statistically significant correlation between US findings and Q B-hCG findings. When the size of the adnexal mass increased in US examination, the level of $\mathrm{Q}$ $\mathrm{B}-\mathrm{hCG}$ was detected to be elevated and vise vesra.P value $<0.05$.

Table (7) shows that 43 patients (79.6\%) respond well to methotrexate with minimal side effects as conjunctivitis and stomatitis, 2 patients $(3.7 \%)$ respond well to methotrexate but with rare side effects .,the $1^{\text {st }}$ case show epistaxis from thrombocytopenia (platelet count les than $150.000 / \mathrm{cmm}$ ), while the $2^{\text {nd }}$ case show persistent cough from pneumonia,6 patients $(11.1 \%)$ need laparoscopic management and 3 patients $(5.6 \%)$ need urgent laparotomy.

Table (8) shows that 44patients $(81.48 \%)$ need single dose of methotrexate .10 patients $(18.52 \%)$ need multiple doses one week a part a second dose of methotrexate 50 $\mathrm{mg} / \mathrm{m}^{2}$ was given, the causes of that as the level of quantitive beta subunite was greater than five thousands $\mathrm{mIU} / \mathrm{mL}$ in 3 cases, the size of the adnexal mass was more than $3 \mathrm{~cm}$ in other 2 cases, decline in Q B-hCG between day 4 and 7 was less than $15 \%$ in the other 5 cases ( 7 of them need 2 doses and the other 3 cases need 3 doses of methotrexate ). 6 patients $(11.1 \%)$ need laparoscopic management 4 of them due to pain intolerance while the other 2 cases due to failure of medical treatment as Q B-hCG falled $<15 \%$ between weekly measurement after third dose, so laparoscopic salpingostomy or salpingectomy was performed. 3 patients $(5.6 \%)$ need urgent laparotomy 2 of them were presented with hemodynamic instability, and 1 with acute abdomen with high initial Q B-hCG levels. 
Table (1): Demographic data of the studied cases of undisturbed ectopic pregnancy.

\begin{tabular}{lllll}
\hline & $\mathbf{n}=\mathbf{5 4}$ & p. value & \\
\hline Age (years) & & & \\
\hline Mean \pm SD & $27.9 \pm 4.5$ & 0.42 & $\mathrm{NS}$ \\
\hline Range & $20-38 \mathrm{Y}$ & & \\
\hline Gestational age at diagnosis & & & \\
\hline Mean \pm SD & $6.7 \pm 1.0$ & 0.35 & $\mathrm{NS}$ \\
\hline Range & $5-8 \mathrm{Ws}$ & & \\
\hline
\end{tabular}

Table (2): Effect of previous mode of delivery,previous abortion and parity on the incidence of ectopic pregnancy.

\begin{tabular}{llllll}
\hline \multirow{2}{*}{ Mode of delivery } & & N & \% & \multicolumn{2}{c}{ p.value } \\
\hline \multirow{2}{*}{ Parity } & NVD & 31 & $69.8 \%$ & \multirow{2}{*}{0.57} & NS \\
\cline { 2 - 6 } & CS & 13 & $30.2 \%$ & \multirow{2}{*}{0.38} & NS \\
\hline \multirow{2}{*}{ Abortion } & $1-3$ & 37 & $67.9 \%$ & $32.1 \%$ & NS \\
\cline { 2 - 6 } & $4-7$ & 17 & $69.8 \%$ & 0.40 & \\
\hline
\end{tabular}

Table (3): Incidence of previous ectopic, previous PID and contraception IUD on incidence of ectopic pregnancy.

\begin{tabular}{|c|c|c|c|c|c|}
\hline & & $\mathbf{N}$ & $\%$ & & \\
\hline \multirow{2}{*}{ Previous ectopic pregnancy } & -ve & 50 & $92.6 \%$ & \multirow{2}{*}{0.20} & \multirow{2}{*}{ NS } \\
\hline & $+\mathrm{ve}$ & 4 & $7.4 \%$ & & \\
\hline \multirow{2}{*}{$\begin{array}{l}\text { History of pelvic inflammatory } \\
\text { disease }\end{array}$} & -ve & 43 & $79.6 \%$ & \multirow{2}{*}{0.59} & \multirow{2}{*}{ NS } \\
\hline & +ve & 11 & $20.4 \%$ & & \\
\hline \multirow{2}{*}{ Contraception(IUD) } & -ve & 35 & $64.2 \%$ & \multirow{2}{*}{0.46} & \multirow{2}{*}{ NS } \\
\hline & $+\mathrm{ve}$ & 19 & $35.8 \%$ & & \\
\hline
\end{tabular}


Table (4):Clinical presentation of the study population.

\begin{tabular}{|c|c|c|c|c|c|}
\hline & & $\mathbf{N}$ & $\%$ & & \\
\hline \multirow{2}{*}{ Vaginal bleeding } & -ve & 18 & $35.2 \%$ & \multirow{2}{*}{0.47} & \multirow{2}{*}{ NS } \\
\hline & + ve & 35 & $64.8 \%$ & & \\
\hline \multirow{2}{*}{ Abdominal pain and tenderness } & -ve & 2 & $3.7 \%$ & \multirow{2}{*}{0.13} & \multirow{2}{*}{ NS } \\
\hline & $+\mathrm{ve}$ & 52 & $96.3 \%$ & & \\
\hline \multirow{2}{*}{ Amenorrhea } & -ve & 4 & $7.4 \%$ & \multirow{2}{*}{0.11} & \multirow{2}{*}{ NS } \\
\hline & $+\mathrm{ve}$ & 50 & $92.6 \%$ & & \\
\hline
\end{tabular}

Table (5): Comparison between the cases who required single methotrexate dose and who required multiple doses of methotrexate as regard pre treatment, $4^{\text {th }}$ day and $7^{\text {th }}$ day level of Q B-hCG.

\begin{tabular}{|c|c|c|c|c|}
\hline & $\begin{array}{c}\text { Single dose } \\
\text { (resolvedgroup) } \\
(\mathrm{n}=\mathbf{4 4}) \\
\end{array}$ & $\begin{array}{l}\text { Multiple dose }(\geq 2 \text { doses }) \\
(n=10)\end{array}$ & $\mathbf{T}$ & $\mathbf{P}$ \\
\hline \multicolumn{5}{|l|}{ Pre } \\
\hline Mean \pm SD & $4231.9 \pm 2210.3$ & $5626 \pm 1417.7$ & 1.89 & $>0.05$ \\
\hline Range & $397-7102$ & $3430-7200$ & & \\
\hline \multicolumn{5}{|l|}{$4^{\text {th }}$} \\
\hline Mean $\pm S D$ & $3881.7 \pm 2317.6$ & $6230.5 \pm 1063.7$ & 3.11 & $<0.001$ \\
\hline Range & $107-7400$ & $4005-7800$ & & \\
\hline \multicolumn{5}{|l|}{$7^{\text {th }}$} \\
\hline Mean $\pm S D$ & $2566.9 \pm 2145.6$ & $6189.0 \pm 1192.3$ & 5.13 & $<0.001$ \\
\hline
\end{tabular}

Table(6):Ultrasound adnexal mass size correlated to success of treatment. The mass ranged from 8 to $32 \mathrm{~mm}$, the mean was $23.3 \pm 7.2$.

\begin{tabular}{ccc}
\hline Adnexal mass $(\mathbf{c m})$ & No & Successful \\
\cline { 2 - 3 } & 32 & $\mathbf{1 0 0 \%}$ \\
\hline $\begin{array}{c}\mathbf{0 - 2} \\
\mathbf{n}=\mathbf{3 2})\end{array}$ & 13 & $\mathbf{5 9 . 0 9 \%}$ \\
\hline $\begin{array}{c}>\mathbf{2} \\
(\mathbf{n}=\mathbf{2 2})\end{array}$ & 32 & \\
\hline
\end{tabular}




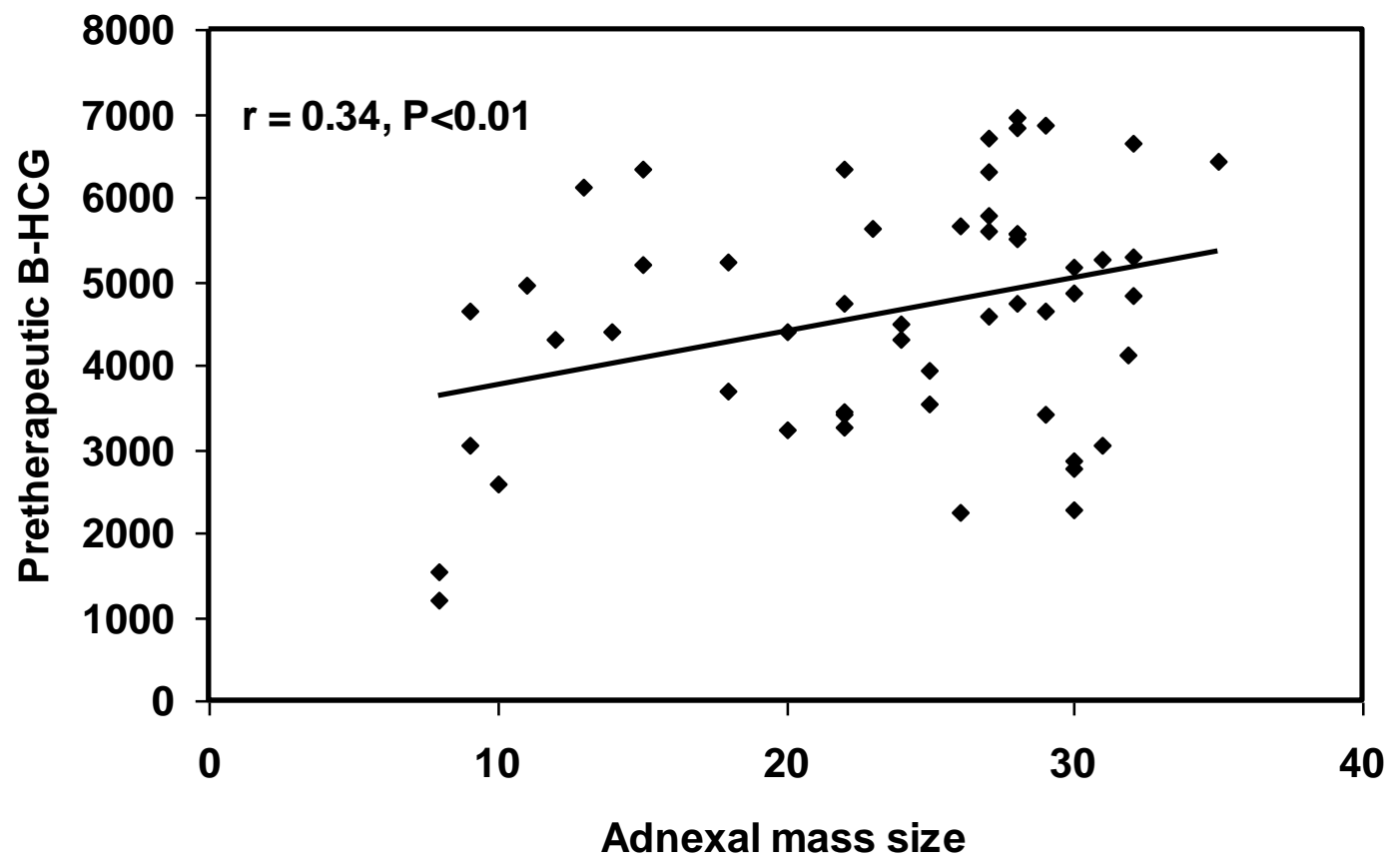

Fig. (1): Significant correlation between the adnexal mass size and the pretherapeutic Q B-hcG.

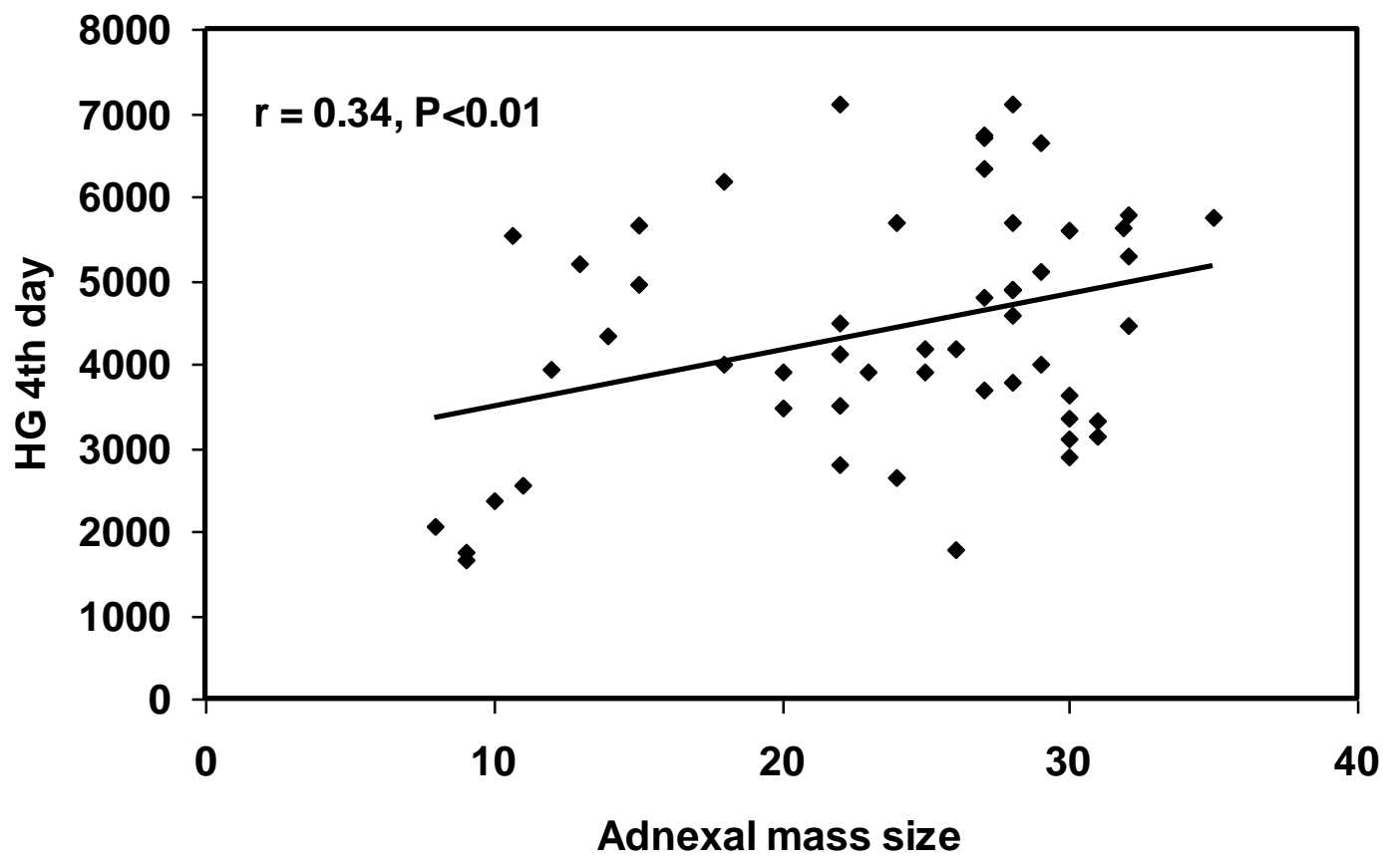

Fig. (2): Significant correlation between the adnexal mass size and the Q B-hcG in the fourth day of medical treatment. 


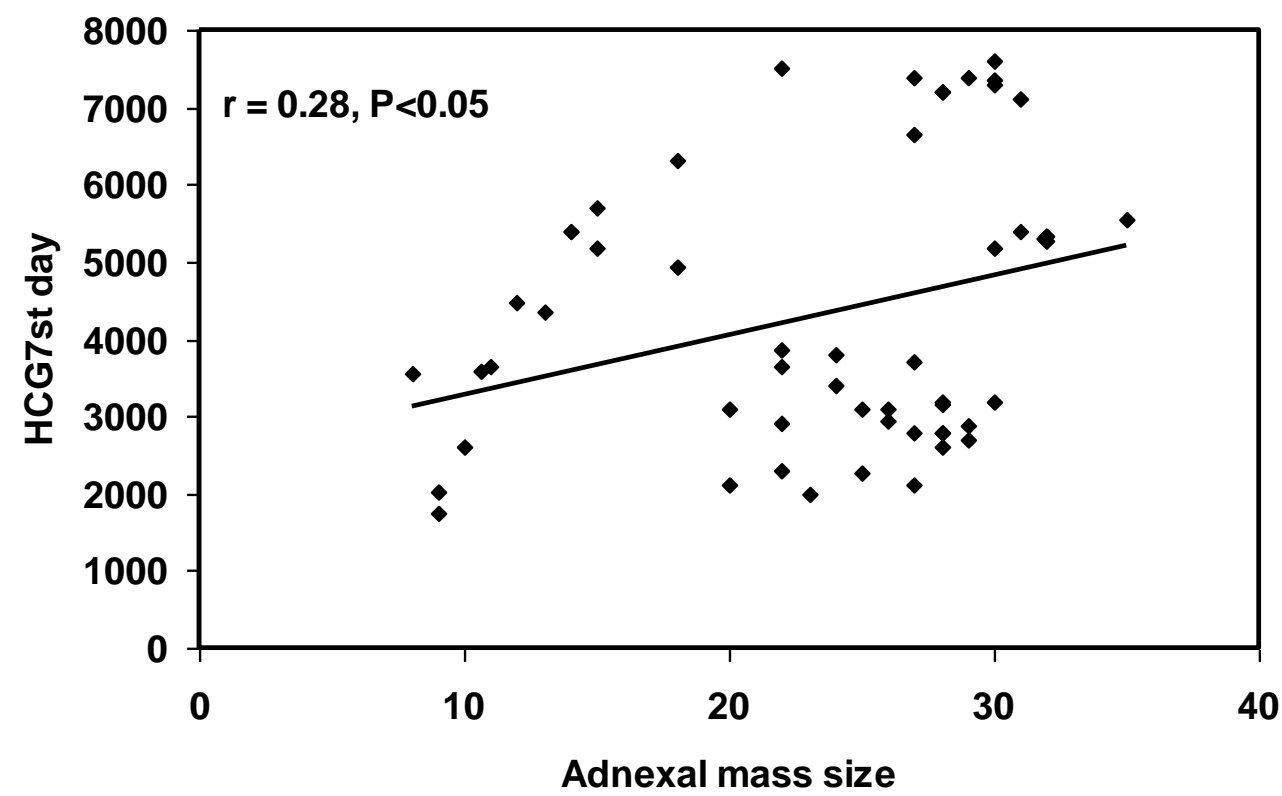

Fig. (3): Significant correlation between the adnexal mass size and the Q B-hcG in the seventh day of medical treatment by methotrexate.

Table (7): Response to methotrexate treatment in the study population.

\begin{tabular}{lcc}
\hline & No & $\%$ \\
\hline Patients respond well to therapy with minimal side effects & 43 & 79.6 \\
\hline Patients respond with some side effects & 2 & 3.7 \\
\hline Patients need laparoscopic management & 6 & 11.1 \\
\hline Patients need urgent laparotomy & 3 & 5.6 \\
\hline
\end{tabular}

Table (8): Mode of treatment of undisturbed ectopic pregnancy in the study population.

\begin{tabular}{lcc}
\hline Mode of treatment & N & \% \\
\hline Methotrexate & & 81.48 \\
\hline Single dose & 44 & 18.52 \\
\hline Multiple dose & 10 & \\
\hline Patient need laparoscopy & & 88.88 \\
\hline -ve & 48 & 11.12 \\
\hline$+v e$ & 6 & 94.44 \\
\hline Patient need laparotomy & 51 & 5.56 \\
\hline -ve & 3 & \\
\hline$+\mathrm{ve}$ & & \\
\hline
\end{tabular}




\section{DISCUSSION}

This study was carried out in outpatient clinic of Zagazig University Maternity Hospital between August 2012 to December 2014. The study included 54 pregnant patients with undisturbed ectopic pregnancy at time of presentation who were managed by conservative medical treatment with methotrexate.

The aim of this study was to evaluate the role of conservative medical treatment of undisturbed ectopic pregnancy with methotrexate .

In this study the clinical presentation of pregnant patients may be by vaginal bleeding that presented in 35 patients $(64.8 \%)$ or lower abdominal pain presented in 52patients( $97.3 \%$ ) or amenorrhea presented in 50 patients $(92.6 \%)$.

Fletche Elson $\mathbf{J}$ et al. ${ }^{(8)}$ stated that pain and bleeding may occur together in about $1 / 3$ of patient with ectopic pregnancy.

In this study, 15 patients $(27.8 \%)$ had risk factors of ectopic pregnancy either due to previous ectopic (4 patients $7.4 \%$ ) or symptoms of PID (11 patients $20.3 \%$ )This was found to be in accordance with Shaw JL, Dey SK, et al. ${ }^{(9)}$ who revealed that risk of ectopic pregnancy increases approximately 3 folds for women with documented tubal pathology.

In this study, 19 patients $(35.8 \%)$ used IUD which was removed on diagnosis of ectopic pregnancy. Previous exposure to abdominal or pelvic surgery was recorded in 13 patients(24.1) as previous CS or previous abortion that recorded in16 patients(29.6).

Gamzu R, Almog B, Levin Y et al. ${ }^{(10)}$ demonstrated the success with the single-dose regimen to be $88.1 \%$, while the success with the multiple dose regimen was $92.7 \%$.

In this study, 44 patients $(81.48 \%)$ need single dose of methotrexate ,10 patients (18.52\%) need multiple doses one week a part.

In this study there was no statistical significant difference as regard the mean size of adnexal mass as there were 32 case with adnexal mass size from $0-2 \mathrm{~cm}$ and success rate of treatment was $100 \%$, while there were 22 case with adnexal mass size more than
$2 \mathrm{~cm}$ out of them 13 case were cured with success rate $59.09 \%$.

Hopkisson J. et al. ${ }^{(11)}$ also demonstrated the single-dose regimen to have a slightly higher failure rate.

In the current study it was found that ectopic pregnancy was resolved by methotrexate treatment in 45 patients $(83.3 \%)$ and the remaining 9 patients $(16.7 \%)$ needed surgical interference 6 patients $(11.1 \%)$ need laparoscopic management 4 of them due to pain intolerance while the other 2 cases due to failure of medical treatment as Q B-hCG falled $<15 \%$ between weekly measurement after third dose, so laparoscopic salpingostomy or salpingectomy was performed, 3 patients $(5.6 \%)$ need urgent laparotomy 2 of them were presented with hemodynamic instability, and 1 with acute abdomen with high initial Q B-hCG levels.

- Mol F, van den Boogaard E,van Mello Nm, et al. ${ }^{(12)}$ stated that reported success rates of single dose methotrexate range 65 to $95 \%$.

In current study, there was a statistical significant lower mean Q B-hCG level in resolved group when compared to surgical group at $4^{\text {th }}$ and $7^{\text {th }}$ day of follow up $\mathrm{P}<0.05$. On the $4^{\text {th }}$ day, there was statistical significant lower Q B-hCG level with a mean level of $3881.7 \pm 2317.6 \mathrm{mIU} / \mathrm{ml}$ lower than the pretreatment Q B-hCG in resolved group . On the $7^{\text {th }}$ day, there was statistical significant decrease in Q B-hCG level and its mean was $2566.9 \pm 2145.6 \mathrm{mIU} / \mathrm{ml}$ in resolved group.

In surgical group, there were no statistical significant changes between $Q$ B-hCG level at 4th day and after 7th day.

To do comparison between our study and other studies the success rate in other studies was found to be more than in our study, this due to the beginning of starting the MTX injection in our studied populations with increasing quantitive beta subunite values and complaints of abdominal pain were taken early for surgical intervention for fear of rupture of the EP. With more experience of using the drug, the success rate will be increased .

Accurate detection of cases and stricte selection to the inclusion criteria of low 
quantitive beta subunite levels, size of adnexal mass is less than $3.5 \mathrm{~cm}$ and good clinical procedures avoided early surgical intervention and improvement of the success rate is year by year(13).

Srivichai K et al. ${ }^{(14)}$ reported a success rate of ninety point six percent in ninety six out of one hundered and six patients were successfully treated with MTX though 4 of them need a 2 nd dose. Success reached ninety percent $(n=10)$ in patients out of eleven with single dose treatment.

Merisio et al. ${ }^{(15)}$ Failure of MTX treatment is due to a high increase in quantitive beta subunite level from $4^{\text {th }}$ to $7^{\text {th }}$ day after injection.

There is marked increase in size of EP and may persist for weeks on serial US examinations after injection,this may be represents hematoma formation rather than persistent trophoplastic tissue, and is not prediction of medical treatment failure.Also increase in quantitive beta subunite levels in three days following medical treatment (up to 4th day ) this may be due to continouse production of human chorionic gonadotrophin hormon by syncytiotrophoblast despite cessation of production by cytotrophoblast(16).

Sensation of pain after MTX treatment may be due to abortion through the tube or hematoma formation that cause stretch of the tube that may contribute withtubal rupture and failure of medical therapy ${ }^{(17)}$.

Fearing of tubal rupture misleads clinicians to do early surgical intervention on unruptured EP that may be resolve with medical MTX therapy.

It is diffecult to differentiate between separation pain due to tubal abortion from pain due to tubal rupture and this may lead to early surgical intervention(18).

Mamdoh $^{(19)}$ demonstrated that quantitive beta subunite of two thousands $\mathrm{mIU} / \mathrm{ml}$ is an optimum value for selecting cases for medical failure using the single dose approach as cases with initial quantitive beta subunite value of more than two thousands $\mathrm{mIU} / \mathrm{ml}$ and/or in embryonic sac is more than three point four $\mathrm{cm}$ should be closely monitored for failure of medical treatment.

MTX regimen with multiple dose for haemodynamically stable women with an unruptured tubal EP with serum quantitive beta subunite concentrations less than three thousands $\mathrm{mIU} / \mathrm{ml}$ and a single-dose of MTX for serum quantitive beta subunite less than one thousand and five hundereds $\mathrm{mIU} / \mathrm{ml}$ is recommended. Women with a pretreatment quantitive beta subunite level of three thousands to four thousands $\mathrm{mIU} / \mathrm{ml}$ have more probability of surgical intervention or multiple dose treatment ${ }^{(20)}$.

Persistent of EP after laparotomy with conservation of the tube was three to five percent and after laparoscopy was three to tweenty percent.Administration of MTX decrease the incidence of persistent trophoblast. Persistent trophoblast is detected by the failure of serum quantitive beta subunite levels to fall as expected after initial treatment, olften a problem occurring after salpingotomy rather than salpingectomy ${ }^{(21)}$.

\section{CONCLUSION}

From the current study we concluded that there is no pathognomonic pain or findings on examination that are diagnostic for tubal pregnancy.Also the diagnosis of tubal pregnancy, as early as 6-7 weeks postmenstrual by screening of all suspected pregnancies may be the key for optimal use of medical treatment.

TVUS and serial quantitive beta subunite are highly successful in early detection of EP.

The treatment of ectopic pregnancy, no longer necessarily requires laparotomy or laparoscopic management. Medical management by methotrexate injection is safe approach for the resolution of ectopic pregnancy proplem.

\section{REFERENCES}

1- Fylstra DL. Tubal pregnancy: a review of current diagnosis and treatment of ectopic pregnancy. Surv 1998; 53: 320.

2- Scott L. An alternative to surgery in treating ectopic pregnancy. Nurs Times. 2006; 102(18): 24-6.

3- Stovall TG, Ling FW, Carson A, et al. Serum progesterone and uterine curettage in differential diagnosis of ectopic pregnancy.

Fertil Steril 2005; 57(2): 456-7.

4- Dilbaz, Eray Caliskan, Berna Dilbaz, Ozlem Degirmenci, and Ali Haberal. Predictors of Methotrexate Treatment Failure in Ectopic 
Pregnancy. The Journal of Reproductive Medicine 2006.

5- Yankowitz J, Leake J, Huggins G, et al. Cervical ectopic pregnancy: A review of the literature and report of a case treated by single dose methotrexate therapy. Obstetrical and Gynecological Surgery 2009; 45: 405-414.

6- Barnhart K, Gosman M, Ashby R, et al. The medical management of ectopic pregnancy: A meta-analysis comparing "single-dose" and "multi-dose" regimens. Obstetrics and Gynecology 2003; 101: 778-784.

7- Centers for Disease Control and Prevention. Ectopic pregnancy: United States 2006-2008. Morbidity and Mortality Weekly Report 2009; 44: 46-48.

8- Fletche Elson J, Tailor A, Banerjee S, Salim R, Hillaby K, Jurkovic D. Expectant management of tubal ectopic pregnancy: prediction of successful outcome using decision tree analysis. Ultrasound Obstet Gynecol 2011; 23: 552-556.

9- Shaw JL, Dey SK, Critchley HO, et al. Current knowledge of the aetiology of human tubal ectopic pregnancy. Hum Reprod Update 2010; 16(4): 432-44.

10- Gamzu R, Almog B, Levin Y Pauzner D, Lessing JB, Jaffa A, Bar-Am A. The ultrasonographic appearance of tubal pregnancy in patient treated with methotrexate. Hum Reprod 2006; 17: 2585-2587.

11- Hopkisson J. The management of ectopic pregnancy. Current Obstetrics and Gynaecology 2005; 15: 343-347.

12- Mol F, van den Boogaard E,van Mello Nm, et al.(2011): guideline adherence in ectopic pregnancy management. Hum Reprod;26(2):307-15.
13- Moeller LB, Moelle C, Thomsen SG, et al.(2009):Success and spontaneous pregnancy rates following systemic methotrexate versus laparoscopic surgery for tubal pregnancies: Arandomized trial.Acta Obstet Gynecol Scand;1-7.

14- Hoover KW,Tao G,Kent CK(2010):Trends in the diagnosis and treatment of ectopic pregnancy in the United States. Obstet Gynecol;115(3):495-502.

15- Srivichai K, Urtavichai C, Tongsong T. Medical treatment of ectopic pregnancy: A tenyear review of 106 cases at Maharaj Nakorn Chiang Mai Hospital. J Med Assoc Thai 2006; 89(10): 1567-1571.

17- Merisio C, Anfuso S, Berretta R, et al. Singledose methotrexate for ectopic pregnancy treatment: Preliminary data. Acta Bio Med 2005; 76: 33-36.

18- Stein JC,Wang R, Adler N, et al.(2010) Emergency physician ultrasonography for evaluation patients at risk for ectopic pregnancy:a meta- analysis.Ann Emerg Med;56(6):674-83 19- Mamdoh E. Single dose methotrexate for treatment of ectopic pregnancy: Risk factors for treatment failure. Middle East Fertility Society Journal 2007; 12: 57-62.

20- Soliman KB, Saleh NM and Omran AA. Safety and efficacy of systemic methotrexate in the treatment of unruptured tubal pregnancy. Saudi Med J 2006; 27(7): 1005-1010.

21-Mol E, Mol BW, Ankum WM, et al. Current evidence on surgery, systemic methotrexate and expectant management in the treatment of tubal ectopic pregnancy: A systematic review and meta-analysis. Hum Reprod Update 2008; 14(4): 309-319. 